\title{
Aggregate PP Interval
}

National Cancer Institute

\section{Source}

National Cancer Institute. Aggregate PP Interval. NCI Thesaurus. Code C117771.

An aggregate PP value based on the measurement of PP intervals from multiple beats

within a single ECG. The method of aggregation, which can vary, is typically a measure of central tendency such as the mean. (CDISC) 